\title{
Leydig Cell Tumor: A Case Report
}

\author{
Amatya $\mathbf{N}^{1}$, Zhu $\mathbf{M}^{2}$, Sapkota $\mathbf{P} \mathbf{K}^{1}$ \\ ${ }^{1}$ Radiology Unit, Helping Hands Community Hospital, Kathmandu, Nepal, ${ }^{2}$ Department of \\ Diagnostic Ultrasound, West China Hospital of Sichuan University, Chengdu, China
}

\begin{abstract}
Leydig cell tumor is a relatively uncommon tumor clinically presenting with gynecomastia, increased sex hormone levels (i.e. testosterone and estradiol) and other correlated symptoms. However, preoperative ultrasonic diagnosis is difficult especially when the clinical manifestations are unremarkable. We report a case of Leydig cell tumor of testis that presented with atypical features.
\end{abstract}

Keywords: Leydig cell tumor, Neoplasm, Testosterone, Ultrasonography

\section{Introduction}

Leydig cell tumor (LCT) is a rare entity among testicular neoplasm. It can occur at any age, typically between 30 and 60 years of age. Due to variable appearance, it can be challenging to distinguish between germ cell tumor and LCT. Sonographic imaging is still a problem in diagnosing this entity and hence easily can be misdiagnosed. ${ }^{1}$ We report a case of LCT sonographically presenting with atypical features of "thin tubular structures" and color Doppler USG revealing a marked hypervascularity pattern highlight the ultrasonography-histological correlation.

\section{Case Report}

A 46 year old man presented with scrotal swelling for more than one year. Genital examination found that the right scrotum was swollen with mild tenderness. The laboratory examination revealed normal

Correspondence to: Dr. Nabin Amatya, MD Radiology Unit, Helping Hands Community Hospital Kathmandu, Nepal Email:naabbin@hotmail.com
AFP and HCG. Enhanced-abdominal CT revealed that the both adrenal glands were normal. However, enhanced CT revealed a homogenously enhanced right intratesticular

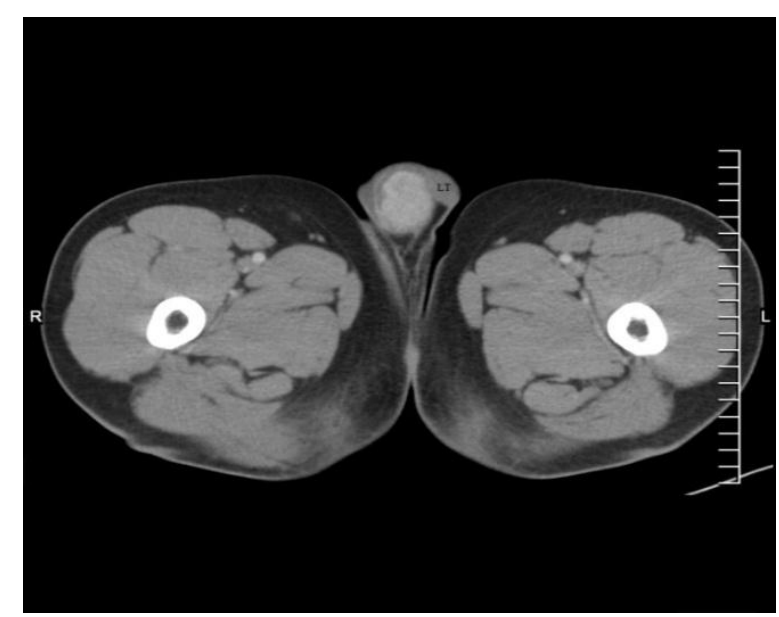

Fig 1: CT scans of 46-year-old male with Leydig cell tumor. Enhanced CT shows a hyperdense enhancing tumor. Note that the left testis (LT) is unremarkable.

nodule of size $3.0 \times 2.0 \mathrm{~cm}$ with clear border and margin (Figure1). Ultrasound examination is a non invasive and nonionising tool and it has been widely used in examination of scrotum. During B-mode examination, size of $3.0 \quad \mathrm{x}$ 


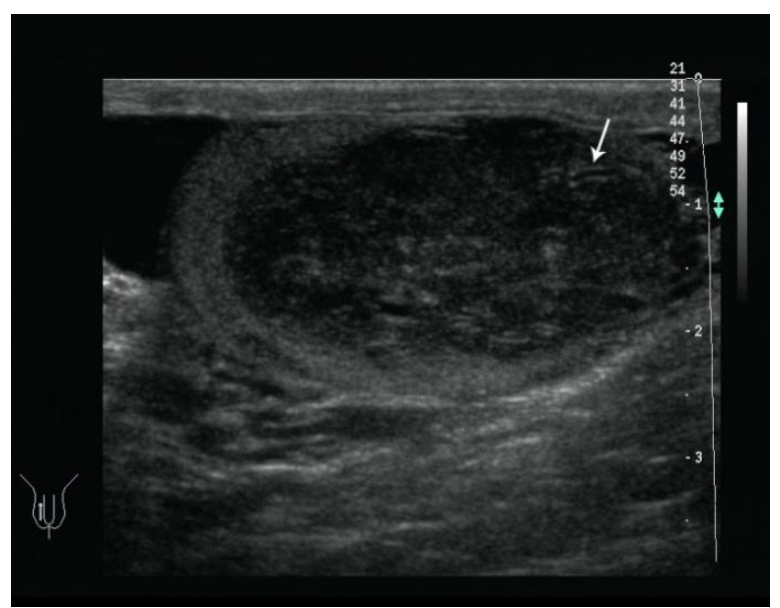

Fig 2a: Sonogram showing a homogeneously hypoechoic tumor (white arrow).

$2.1 \mathrm{~cm}$ solid nodule was found in the right testis. The nodule was well-defined and heterogeneous hypoechoic with thin tubular structure (Figure 2a). Color Doppler demonstrated hypervascularity inside the nodule (Figure 2b). Pathological examination revealed an intratumoral abundance of blood vessels and prominent vascularity surrounding the lesion which corresponded to the ultrasonographic imaging feature. Tumor cells were seen to grow in sheets and infiltrated growth around the seminiferous tubule (Figure3).

\section{Discussion}

The common tumor among non-germ cell neoplasms of the testis is Leydig cell tumor, accounting for $1 \%-3 \%$ of testicular tumors in adults and $4 \%$ in prepubertal children. About $90 \%$ of LCTs are benign. ${ }^{2-4}$ Clinically, testosterone, estradiol and other sex hormone levels may rise and the patients present with precocious puberty, gynecomastia, impotence, and virilization. In our case, laboratory examination was unremarkable for testosterone level.

Undoubtedly, ultrasound plays an important role in the diagnosis of scrotal disease. In the literature, various patterns of echogenicity have been described for Leydig cell tumor. These include hypoechoic nodule, isoechoic

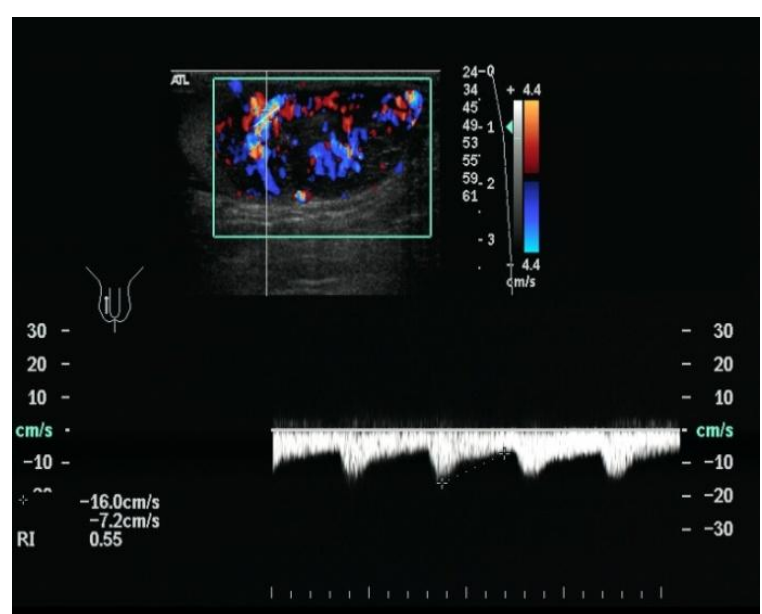

Fig 2b: Doppler image showing multivascularity of the tumor.

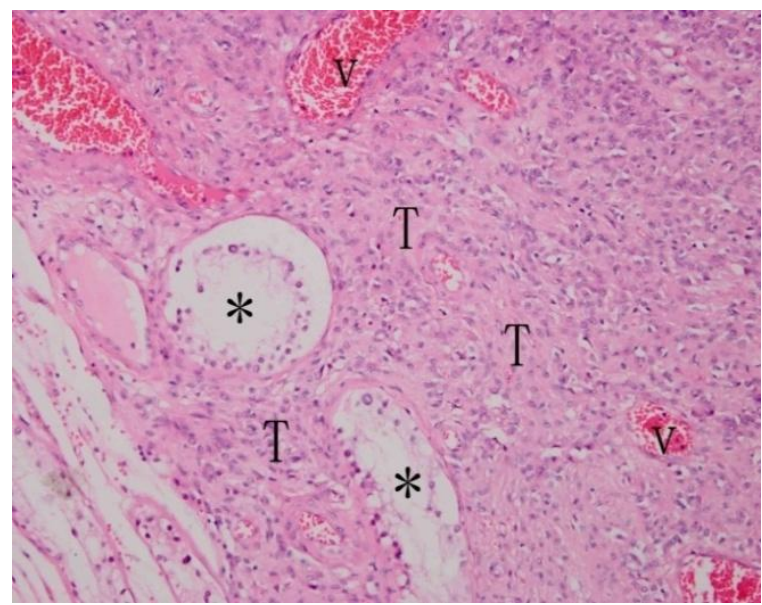

Fig 3: Histological section (x200, hematoxylin-eosin staining) showing multiple vessels (V) and the seminiferous tubule (asterisk) in the lesion (T).

nodule or hyperechoic appearances , infrequently presenting with calcification. ${ }^{5-8}$ In our case, the nodule was small and heterogeneously hypoechoic. In addition, in our case we observed the "thin tubular structure" which is an atypical feature.

Seminoma is the most common germ cell tumor and its sonographic appearance is typically a homogeneous well-defined hypoechoic lesion. LCT is indistinguishable from germ cell tumors sonographically, although a high level of testosterone and estradiol, gynecomastia and an intratesticular tumor seen in ultrasound may be suggestive 
of LCT. Doppler study showed profuse blood flow signal inside the mass, similar to that of the testicular malignancy. In the literature, the following types of vascular patterns of LCT have been reported: (a) Hypo-vascular appearance. (b) A large feeding vessel leading into the mass. (c) The prominent peripheral and circumferential blood flow, contrasted with the lack of internal vascularity. (d) Marked hypervascularity. 5,7,9 In our case, marked hypervascularity was seen.

\section{Conclusion}

The clinical features LCTs are characteristic and should alert the clinician to the likelihood of an underlying LCT, which should be evaluated by laboratory and ultrasonographic examination.

\section{Acknowledgements}

This study was supported by Dr Li Fei and Associate Prof Liu Rong Bo from the Department of Radiology of the West China Hospital, Chengdu, China.

\section{References}

1. Woodward PJ, Sohaey R, O'Donoghue $\mathrm{MJ}$, et al. Tumors and tumor like lesions of the testis: radiologic-pathologic correlation. Radiographics 2002; 22:189-216.

2. Kim I, Young RH, Scully RE. Leydig cell tumors of the testis: a clinicopathological analysis of 40 cases and review of the literature. Am J Surg Pathol 1985;9:177-192.

3. Henderson CG, Ahmed AA, Sesterhenn I, et al. Enucleation for prepubertal Leydig cell tumor. J Urol 2006;176:7035.

4. Sugimoto K, Matsumoto S, Nose K, et al. A malignant Leydig cell tumor of the testis. Int Urol Nephrol 2006;38:291-2.

5. Maizlin ZV, Belenky A, Kunichezky M, et al: Leydig cell tumors of the testis: gray scale and color Doppler sonographic appearance. J Ultrasound Med, 2004; 23:959-64.

6. Corrie D, Norbeck JC, Thompson IM, et al.Ultrasound detection of bilateral Leydig cell tumors in palpable normal testes. J Urol 1987;137:747 -8.

7. Ricci ZJ, Stein MW, Koenigsberg M, et al. Unusual sonographic appearance of a Leydig cell tumor of the testis. Pediatr Radiol 2004;34:177-8.

8. Laks MP, Lustrin E, Molho L, et al. Ultrasound and CT of a calcified Leydig cell tumor. J Comput Assist Tomogr 1992;16:836-7.

9. Horstman WG, Melson GL, Middleton WD, et al. Testicular tumors: findings with color Doppler US. Radiology 1992; 185:733 -7. 